\title{
Reações de oxt-redução e suas diferentes abordagens
}

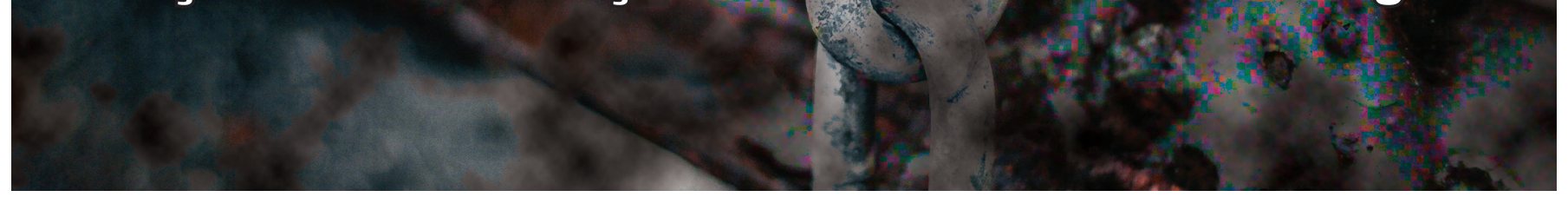

\section{Sabrina G. Klein e Mara E. F. Braibante}

O presente trabalho tem por objetivo apresentar um panorama de como o conteúdo de oxi-redução, considerado de difícil ensino e aprendizagem, vem sendo desenvolvido em sala de aula, a fim de demonstrar suas diversas possibilidades de ensino bem como discutir suas implicações. Para realizar esse panorama realizamos uma busca por artigos publicados na revista QNEsc que abordaram o conteúdo de reações de oxi-redução, na qual foram encontrados 52 artigos. Para isso, escolhemos alguns critérios para verificação das abordagens e cada critério foi classificado em categorias que permitiram uma discussão da forma com que o ensino do conteúdo de oxi-redução vem sendo desenvolvido. Com isso percebemos a diversidade de assuntos que podem ser utilizados como forma de contextualização para abordagem das reações redox e também a variedade de atividades experimentais. Porém, observamos poucas discussões conceituais sobre $\mathrm{o}$ assunto na literatura.

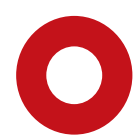

s processos de oxidação e redução fazem parte de uma das principais classes de reações químicas sendo bastante comuns no nosso cotidiano, pois, assim como Joesten e Wood (1996) descreveram, nós vivemos em uma atmosfera oxidante. Ao ingerirmos um alimento, seus nutrientes sofrem diversas reações oxidativas pela ação do oxigênio. Além disso, as reações de oxidação-redução estão presentes em diversas situações fundamentais para o processo evolutivo da tecnologia e indispensáveis para a vida, como a produção de energia elétrica. Segundo Atkins e Jones (2006), as reações redox são extraordinariamente versáteis. Muitas reações comuns, como a combustão, a corrosão, a fotossíntese, o metabolismo dos alimentos e a extração de metais de minério, parecem completamente diferentes, mas ao examinarmos essas reações a nível molecular, sob a óptica de um químico, pode-se ver que elas são exemplos de um único tipo de processo.

De Jong et al. (1995) constataram que os professores percebem as reações redox como um dos tópicos da química mais difíceis de ensinar e os alunos em aprender. Anselme (1997) também ressaltou essa dificuldade em entender a

A seção "Conceitos científicos em destaque" tem por objetivo abordar, de maneira crítica el ou inovadora, conceitos científicos de interesse dos professores de Química. oxidação-redução, principalmente na mudança do domínio da química inorgânica para orgânica, dizendo que às vezes tornam-se experiências traumáticas aos estudantes.

Três importantes dificuldades de aprendizagem apresentadas pelos estudantes descritas em algumas pesquisas são: 1) dificuldade em compreender a oxidação e a redução como reações complementares; 2) dificuldade em identificar os agentes oxidantes e redutores; (De Jong; Treagust (2002 apud Österlund; Berg; Ekborg, 2010); 3) a compreensão que reações redox são definidas como perda e ganho de oxigênio (Österlund; Ekborg, 2009).

Quanto às dificuldades de ensino, De Jong et al (1995) apresentam os principais conceitos e procedimentos relacionados com o conteúdo como causadores de problemas como sendo: transferência de elétrons; identificação de agentes redutores e oxidantes; número de oxidação e seus valores; balanceamento das equações redox e força relativa dos agentes oxidantes e redutores. Para os professores, este estudo verificou que não são levadas em conta as necessidades dos estudantes em aprender novas concepções, oferecendo aos estudantes problemas inadequados, explicações supérfluas, terminologias confusas, ignorando as concepções alternativas, e pouco relacionando o tema com aplicações industriais.

Assim, devido à importância desse conteúdo e por 
apresentar dificuldades de ensino e aprendizagem, o objetivo deste trabalho é investigar como as reações redox estão sendo exploradas a fim de verificar suas diferentes abordagens. Para isso, utilizamos como base, artigos publicados na revista Química Nova na Escola (QNEsc), pois acreditamos que estes nos permitem demonstrar como este conteúdo vem sendo tratado por pesquisadores da área.

\section{Metodologia de Análise}

Este artigo baseia-se em uma revisão bibliográfica dos trabalhos publicados na revista QNEsc sobre o conteúdo de oxi-redução. A escolha desta revista se deve ao fato de sua representatividade no ensino de Química, sendo muito utilizada como referencial por alunos de graduação e professores do ensino médio e superior. $\mathrm{O}$ foco deste trabalho, predominantemente qualitativo, foram os artigos que abordavam, de alguma forma, as reações redox. A busca pelos artigos foi feita pelo site da revista, através das palavras-chave: redox, oxidação, redução, oxi-redução, oxirredução, oxidação-redução, pilhas e eletroquímica. Todos os artigos que apresentavam essas palavras, repetidas durante seu texto, passaram a fazer parte deste trabalho. Para demonstrar as diferentes abordagens escolhemos alguns critérios:

- Quanto à abordagem: teórica ou experimental;

- Quanto ao foco em subáreas da química: inorgânica, orgânica, bioquímica;

- Quanto aos contextos de estudo: científico, tecnológico, social, ambiental;

- Quanto às reações redox: conceitua ou não conceitua, formas de conceituação, uso dos termos número de oxidação e/ou estado de oxidação;

- Quanto ao tema ou assuntos utilizados para seu estudo. Como forma de verificação desses critérios, criamos categorias com base na Análise Textual Discursiva. Esta metodologia de análise de dados, de acordo com Morais (2003), passa pelo processo de desmontagem de textos, que implica em examinar em detalhes os materiais, fragmentando-os para atingir unidades de significados. Em seguida realiza-se o estabelecimento de relações, processo denominado de categorização, onde se constrói relação entre as unidades base, e por fim captando o novo emergente, onde se possibilita a emergência de uma compreensão renovada do todo.

Assim, para o critério abordagem, foram considerados experimentais todos os artigos que apresentaram proposta de realização de alguma atividade experimental e teóricos os que apresentaram apenas questões teóricas. Quanto ao foco em subáreas, averiguamos quais utilizavam reações inorgânicas de oxi-redução e quais os que abordavam reações orgânicas, ou bioquímicas. Quanto ao contexto de estudo, levamos em consideração a percepção dos pesquisadores e também os que apresentaram, de forma escrita, a preocupação em relacionar os conceitos científicos com aspectos, sociais, tecnológicos e ambientais. Para verificar os contextos apresentados nos artigos criamos categorias que estão descritas no Quadro 1.

Quanto às reações redox as seguintes categorias foram criadas: conceituam o conteúdo, não conceituam o conteúdo, utilizam o termo estado de oxidação ou número de oxidação, utilizam ambos os termos, ou ainda, não apresentam nenhum dos termos. Por fim, para o critério tema/assunto, procuramos fazer um levantamento das diferentes abordagens desse conteúdo.

\section{Resultados e Discussões}

Encontramos 52 artigos que abordam reações de oxi-redução, de um total de aproximadamente 550 artigos publicados na revista, no intervalo de tempo de 1995, ano da primeira publicação da revista, até o ano de 2014. Incluímos também artigos que não tinham como foco principal reações de oxi-redução, mas apresentavam este tipo de reação no seu contexto. Esta escolha teve como objetivo demonstrar a diversidade e importância que essas reações assumem. No Quadro 2 listamos por ordem cronológica, todos os artigos localizados na pesquisa sobre $\mathrm{o}$ assunto de reações

Quadro 1: Classificação dos contextos

\begin{tabular}{|c|l|l|}
\hline Categoria & \multicolumn{1}{|c|}{ Significado } & \multicolumn{1}{c|}{ Descrição } \\
\hline C & Científico & Enfoca apenas caráter científico \\
\hline CT & Científico e Tecnológico & Enfoca o caráter científico associado com aspectos tecnológicos \\
\hline CA & Científico e Ambiental & Enfoca o caráter científico associado com aspectos ambientais \\
\hline CS & Científico e Social & Enfoca o caráter científico associado com aspectos sociais \\
\hline CTS & Caráter Científico-tecnológico-social & $\begin{array}{l}\text { Enfoca o caráter científico associado com aspectos tanto tecnoló- } \\
\text { gicos quanto sociais }\end{array}$ \\
\hline CTA & Caráter Científico-tecnológico-ambiental & $\begin{array}{l}\text { Enfoca o caráter científico associado com aspectos tanto tecnoló- } \\
\text { gicos quanto ambientais }\end{array}$ \\
\hline CSA & Científico-social-ambiental & $\begin{array}{l}\text { Enfoca o caráter científico associado com aspectos tanto sociais } \\
\text { quanto ambientais }\end{array}$ \\
\hline CTSA & Científico-tecnológico-social-ambiental & $\begin{array}{l}\text { Enfoca o caráter científico associado com aspectos tanto tecnoló- } \\
\text { gicos quanto sociais e ambientais }\end{array}$ \\
\hline
\end{tabular}


redox. Neste quadro elencamos os critérios estabelecidos em cada artigo e a seguir discutimos cada critério e suas implicações.

\section{Quanto à abordagem}

Através do Gráfico 1, pode-se verificar que dos 52 artigos encontrados que exploram o conteúdo de reações

Quadro 2: Análise dos artigos

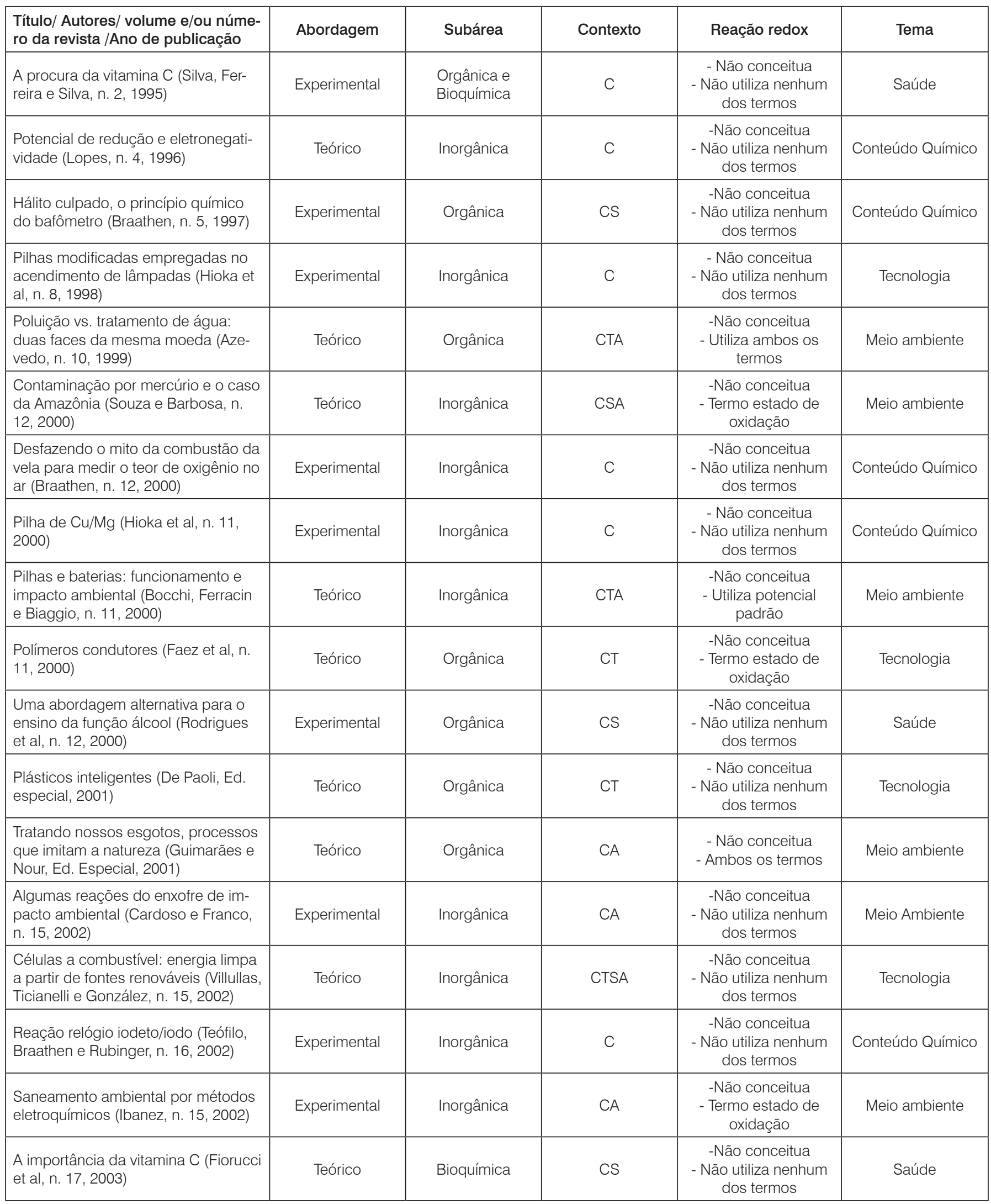




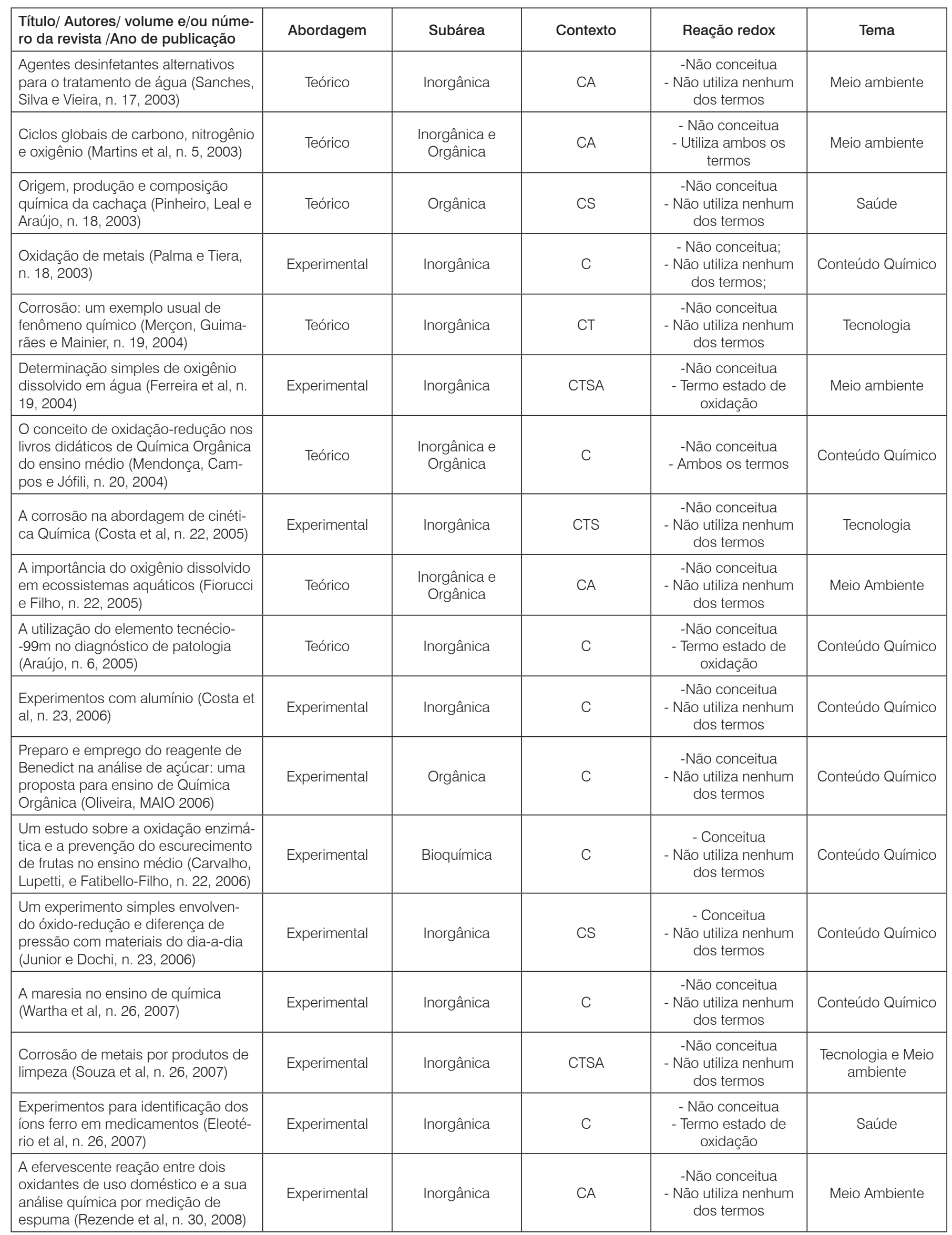




\begin{tabular}{|c|c|c|c|c|c|}
\hline $\begin{array}{l}\text { Título/ Autores/ volume e/ou núme- } \\
\text { ro da revista /Ano de publicação }\end{array}$ & Abordagem & Subárea & Contexto & Reação redox & Tema \\
\hline $\begin{array}{l}\text { A questão do mercúrio em lâmpada } \\
\text { fluorescente (Júnior e Windmöller, n. } \\
28,2008 \text { ) }\end{array}$ & Teórico & Inorgânica & CA & $\begin{array}{l}\text { - Não conceitua } \\
\text { - Termo estado de } \\
\text { oxidação }\end{array}$ & Meio ambiente \\
\hline $\begin{array}{l}\text { Escurecimento e limpeza de objetos } \\
\text { de prata - um experimento simples } \\
\text { e de fácil execução envolvendo rea- } \\
\text { ções de oxidação-redução (Sartori, } \\
\text { Batista e Fatibello-Filho, n. 30, 2008) }\end{array}$ & Experimental & Inorgânica & C & $\begin{array}{l}\text {-Não conceitua } \\
\text { - Termo estado de } \\
\quad \text { oxidação }\end{array}$ & Conteúdo Químico \\
\hline $\begin{array}{l}\text { Maresia: uma proposta para o ensino } \\
\text { de eletroquímica (Sanjuan et al, v. } 31 \text {, } \\
\text { n. } 3,2009 \text { ) }\end{array}$ & Teórico & Inorgânica & C & $\begin{array}{l}\text { - Não conceitua } \\
\text { - Não utiliza nenhum } \\
\text { dos termos }\end{array}$ & Conteúdo Químico \\
\hline $\begin{array}{l}\text { Contextualização do ensino de Quí- } \\
\text { mica em uma escola militar (Scafi, } \\
\text { v. } 32, \text { n. } 3,2010 \text { ) }\end{array}$ & Experimental & Inorgânica & C & $\begin{array}{l}\text { - Não conceitua } \\
\text { - Não utiliza nenhum } \\
\text { dos termos }\end{array}$ & Conteúdo Químico \\
\hline $\begin{array}{l}\text { Sistemas experimentais para o } \\
\text { estudo da corrosão em metais } \\
\text { (Merçon, Guimarães e Mainier, v. 33, } \\
\text { n. 1, 2011) }\end{array}$ & Experimental & Inorgânica & CTSA & $\begin{array}{l}\text {-Não conceitua } \\
\text { - Não utiliza nenhum } \\
\text { dos termos }\end{array}$ & Tecnologia \\
\hline $\begin{array}{l}\text { Uma proposta alternativa para o } \\
\text { ensino de eletroquímica sobre a } \\
\text { reatividade de metais (Fraga et al, } \\
\text { v. } 33, \text { n. } 4,2011 \text { ) }\end{array}$ & Experimental & Inorgânica & CS & $\begin{array}{l}\text {-Não conceitua } \\
\text { - Não utiliza nenhum } \\
\text { dos termos }\end{array}$ & Conteúdo Químico \\
\hline $\begin{array}{l}\text { Aumentando o interesse do alunado } \\
\text { pela química escolar e implantação } \\
\text { da Nova Proposta Curricular Mineira: } \\
\text { desenvolvimento e resultados de } \\
\text { projeto seminal realizado no PIBID-U- } \\
\text { FSJ (Pinheiro, v. 34, n. 4, 2012) }\end{array}$ & Experimental & Inorgânica & CA & $\begin{array}{l}\text { - Não conceitua } \\
\text { - Termo número de } \\
\text { oxidação }\end{array}$ & Meio ambiente \\
\hline $\begin{array}{l}\text { A gota salina de Evans: um expe- } \\
\text { rimento investigativo, construtivo } \\
\text { e interdisciplinar (Matos, Takata e } \\
\text { Banczek, v. } 35, \text { n. } 4,2013 \text { ) }\end{array}$ & Experimental & Inorgânica & C & $\begin{array}{l}\text {-Não conceitua } \\
\text { - Não utiliza nenhum } \\
\text { dos termos }\end{array}$ & Conteúdo Químico \\
\hline $\begin{array}{l}\text { Construção de uma célula eletrolítica } \\
\text { para o ensino de eletrólise a partir de } \\
\text { materiais de baixo custo (Sartori et } \\
\text { al, Vol. } 35, N^{\circ} 2,2013 \text { ) }\end{array}$ & Experimental & Inorgânica & C & $\begin{array}{l}\text { - Conceitua } \\
\text { - Termo estado de } \\
\text { oxidação }\end{array}$ & Conteúdo Químico \\
\hline $\begin{array}{l}\text { A Química dos chás (Braibante et al, } \\
\text { v.. 36, n. 3, 2014) }\end{array}$ & Teórico & Orgânica & $\mathrm{C}$ & $\begin{array}{c}\text {-Não conceitua } \\
\text { - Não utiliza nenhum } \\
\text { dos termos }\end{array}$ & Saúde \\
\hline $\begin{array}{l}\text { Ciência forense no ensino de quí- } \\
\text { mica por meio da experimentação } \\
\text { (Rosa, Silva e Galvan, prelo, 2014) }\end{array}$ & Experimental & $\begin{array}{l}\text { Bioquímica e } \\
\text { Orgânica }\end{array}$ & $\mathrm{C}$ & $\begin{array}{l}\text {-Não conceitua } \\
\text { - Não utiliza nenhum } \\
\text { dos termos }\end{array}$ & Tecnologia \\
\hline $\begin{array}{l}\text { Especiação química e sua impor- } \\
\text { tância nos processos de extração } \\
\text { mineral e de remediação ambiental } \\
\text { (Ladeira et al, n. 8, 2014) }\end{array}$ & Teórico & Inorgânica & CA & $\begin{array}{l}\text { - Não conceitua } \\
\text { - Ambos os termos }\end{array}$ & Meio Ambiente \\
\hline $\begin{array}{l}\text { Origem e controle do fenômeno dre- } \\
\text { nagem ácida de mina (Mello, Duarte, } \\
\text { Ladeira, n. } 8,2014 \text { ) }\end{array}$ & Teórico & Inorgânica & CA & $\begin{array}{l}\text {-Não conceitua } \\
\text { - Não utiliza nenhum } \\
\text { dos termos }\end{array}$ & Meio ambiente \\
\hline
\end{tabular}


redox, $60 \%$ trazem uma abordagem experimental, além de explorar a parte teórica, e $40 \%$ dos artigos apresentam uma abordagem puramente teórica. Destaca-se dessa maneira, a importância das atividades experimentais no âmbito educacional das reações de oxi-redução, onde os artigos analisados demonstraram-se propícios para a aprendizagem do conceito.

A utilização de atividades experimentais no ensino já tem sido alvo de muitos estudos que demonstram sua importância no processo de ensino-aprendizagem. Além disso, revelam que esse tipo de atividade é motivadora, instigante e permite a participação ativa dos estudantes (Giordan, 1999; Galiazzi et al., 2001; Araújo; Abid, 2003; Suart, 2008; Durand, 2015).

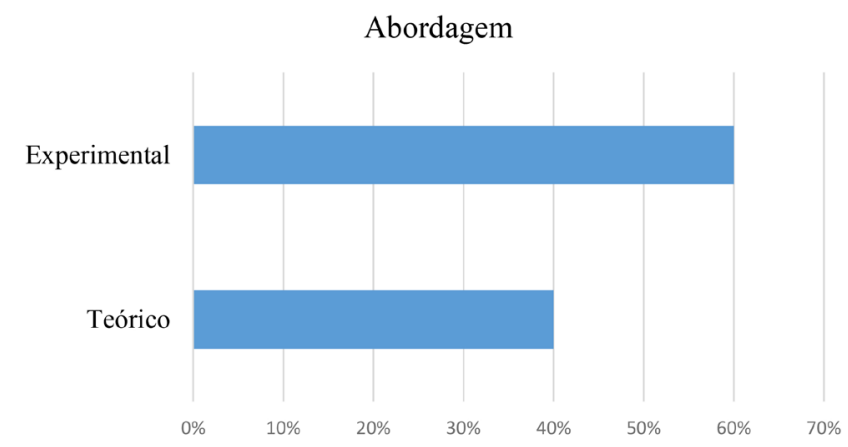

Gráfico 1: Representação percentual do critério Abordagem.

\section{Quanto ao foco em subáreas da química}

Dos artigos localizados, $70 \%$ tinham como foco a química inorgânica, $18 \%$ a orgânica e $3 \%$ a bioquímica. Ainda, $6 \%$ dos artigos apresentavam tanto o enfoque em reações inorgânicas quanto orgânicas, e 3\% em reações bioquímicas e orgânicas (Gráfico 2). Dessa forma, observa-se que são poucos os artigos que exploram as reações redox orgânicas e bioquímicas. A maioria enfoca o ensino das reações inorgânicas, que também são utilizadas na físico-química, abordadas geralmente no currículo do primeiro e segundo ano do nível médio. Apenas alguns poucos artigos não fazem distinção de subáreas e enfocam reações redox na química orgânica e inorgânica juntas, ou bioquímica e orgânica, até mesmo porque um determinado tema ou assunto requer este tratamento.

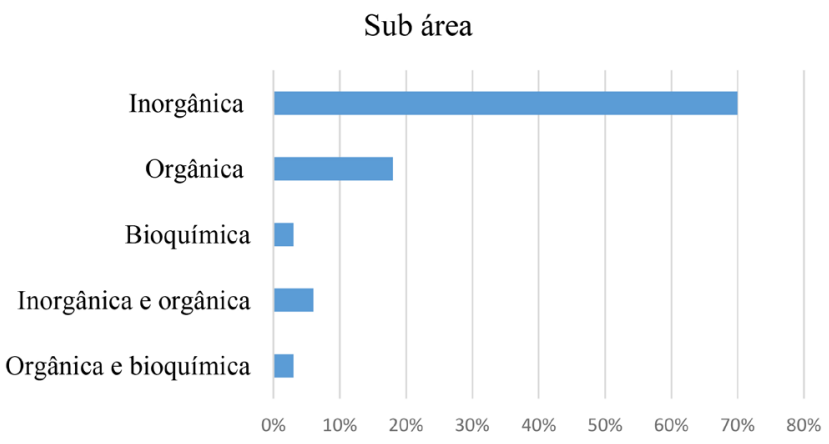

Gráfico 2: Representação percentual do critério Subárea.

Acreditamos que isso se deve à organização curricular atual, que divide o ensino em química inorgânica para o $1^{\circ}$ ano, físico-química para o $2^{\circ}$ ano e orgânica para o $3^{\circ}$ ano. Mas julgamos importante uma abordagem que permita tratar estas questões de forma conjunta, pois pode favorecer a aprendizagem, não levando os estudantes a pensar de forma fragmentada.

\section{Quanto aos contextos de estudo}

Para esse critério, verificamos (Gráfico 3), que o enfoque de caráter apenas científico (C), foi explorado, em $44 \%$ dos artigos encontrados Artigos que relacionavam os conceitos científicos com questões ambientais (CA) somam 22\%. Os que apresentaram aspectos científicos e sociais (CS) foram $11 \%$. Somente $9 \%$ dos artigos associam questões científicas com aspectos tecnológicos, sociais e ambientais (CTSA). Já os artigos com enfoques científico e tecnológico (CT) representam um porcentual de $6 \%$. Artigos com características de científico, tecnológico e ambiental (CTA) representam $4 \%$. Abordagens científica, social e ambiental (CSA) e científico, tecnológico e social (CTS) somam $2 \%$ cada.

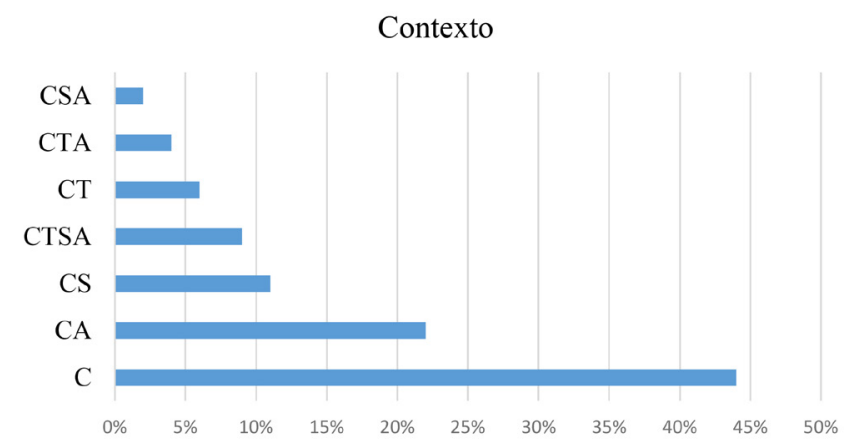

Gráfico 3: Representação percentual do critério Contexto.

As questões puramente científicas estão em maior proporção. Esse fato demonstra que ainda existe muita preocupação com o entendimento científico, o que é importante, mas não o suficiente. São poucos os trabalhos de oxi-redução que abordam além do conhecimento científico, aspectos tecnológicos, sociais e ambientais, que são considerados muito importantes quando se fala na formação cidadã de nossos estudantes. Nessa perspectiva, um enfoque em destaque no ensino de ciência é o da educação CTS, às vezes denominada de CTSA, com o propósito de destacar o compromisso da educação CTS com a perspectiva socioambiental (Santos, 2012), em que um de seus objetivos, apresentado por Auler (2007) é justamente a formação de cidadãos capazes de tomar decisões, sendo científica e tecnologicamente alfabetizados.

O Quadro 3 apresenta alguns trechos dos artigos publicados na revista Química Nova na Escola que representam a categorização utilizada e evidenciamos em negrito as palavras chaves que nos levaram a essa classificação.

Destacamos que nesse espaço analisamos os artigos que tiveram como foco principal o ensino científico relacionado com os outros aspectos citados, não realizamos uma análise crítica a respeito da real implementação desses aspectos, 
Quadro 3: Trechos destacados para análise de contexto.

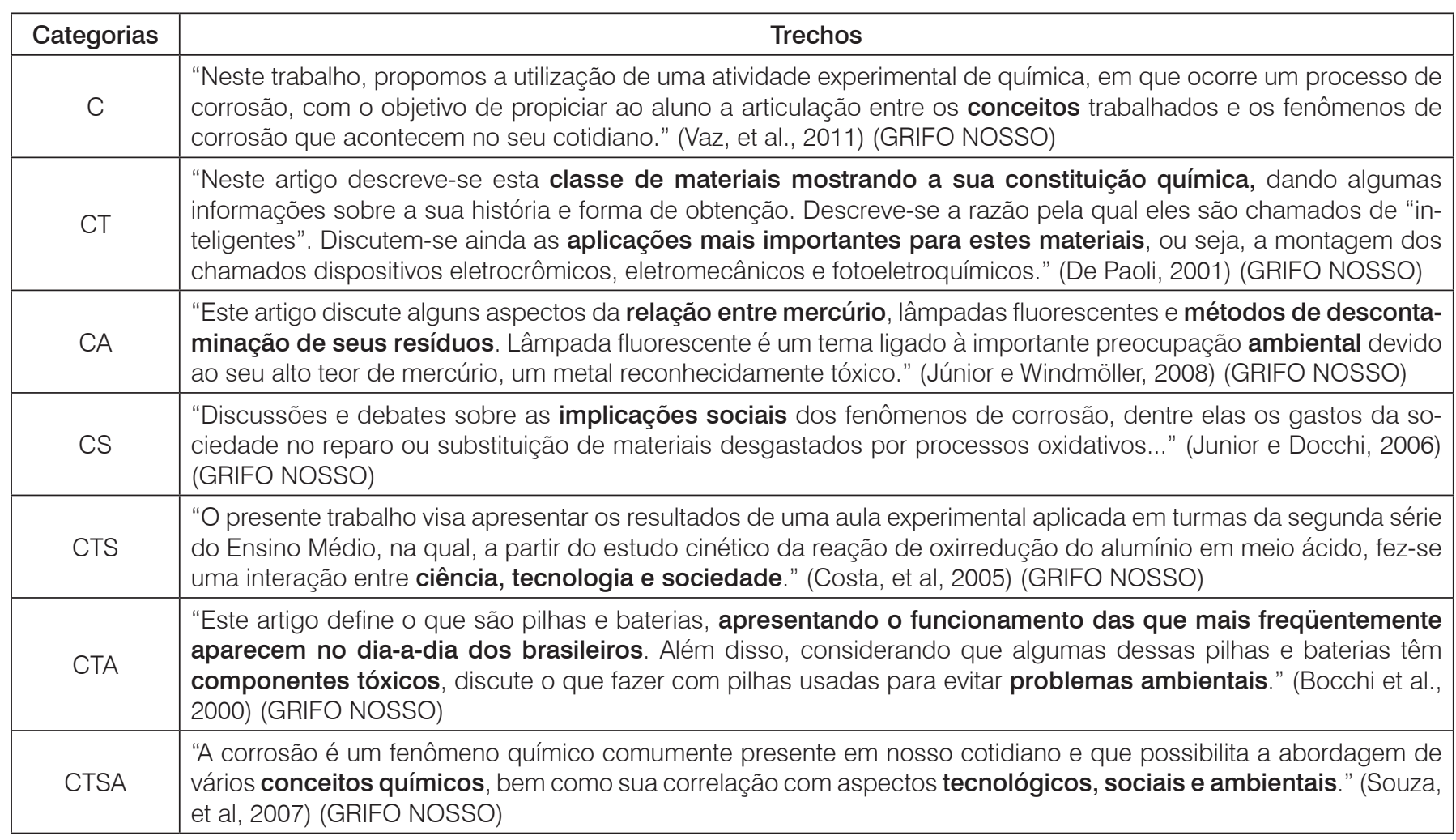

principalmente quando categorizamos como sendo CTS ou CTSA.

\section{Quanto às reações redox}

Dentro desse critério verificamos os artigos que envolvem ou não a conceituação das reações redox. Encontramos apenas $6 \%$ (3 artigos) que conceituavam as reações e assim, os demais, 94\% dos artigos não as conceituavam (Gráfico 4). O Quadro 4 apresenta a forma como os artigos conceituaram as reações redox.

As conceituações apresentadas nos artigos tratam as reações redox como perda e ganho de elétrons, associando isso a mudança de estado de oxidação. Ademais, verificamos que os três artigos que conceituam são do mesmo autor, Fatibello-Filho, e Sartori, aparece em dois deles.

No Quadro 5 selecionamos trechos de alguns artigos que chamaram a atenção por não apresentarem a conceituação de oxi-redução em compostos orgânicos, como apresentado nos dois primeiros exemplos descritos no quadro. Nosso destaque a esse fato se dá pelo motivo do mecanismo das reações de oxi-redução para compostos orgânicos ser diferente do que em compostos inorgânicos, e dessa forma, isso não vem sendo explorado. Fazemos essa afirmação baseados nas diferentes definições existentes para explicar as reações redox.

De acordo com a IUPAC (p. 1048, 2014) a oxidação é: 1) remoção completa de um ou mais elétrons de uma entidade molecular; 2) aumento no número de oxidação de qualquer átomo em qualquer substrato; 3) Ganho de oxigênio ou perda de hidrogênio de qualquer substrato orgânico. Todas as oxidações cumprem os critérios 1 e 2 , e muitas se encontram no critério 3, porém isso nem sempre é de fácil demonstração. Para Ringnes (1995 apud Osterlund; Ekborg, 2009) existem quatro modelos utilizados para a explicação das reações redox: modelo de elétrons, modelo do número de oxidação, modelo do oxigênio e modelo do hidrogênio.

Embora acreditando que o objetivo destes trabalhos não era conceituar reações redox, gostaríamos de destacar que apenas a utilização de atividades diferenciadas para o ensino do conteúdo, principalmente com a realização de atividades experimentais, ao nosso entender, não são suficientes. Consideramos as discussões conceituais básicas importantes para a construção do conhecimento, visto as dificuldades apresentadas no ensino-aprendizagem deste conceito. A nosso ver, as práticas diferenciadas são muito importantes, mas devem ser acompanhadas de conceitos bem definidos para o que o ensino-aprendizagem tenham mais oportunidades de se concretizar.

Como destacado pelo PCNEM (2000), o aprendizado de Química implica em compreender as transformações químicas que ocorrem no mundo físico e esse aprendizado deve possibilitar ao aluno a compreensão tanto dos processos químicos em si quanto da construção do conhecimento científico. Com isso, observamos que a porcentagem de trabalhos analisados que não conceituam as reações de oxi-redução é bastante expressiva e preocupante, levando-se em consideração a importância da apropriação da linguagem científica por parte dos estudantes. 
Quadro 4: Conceituação das reações redox pelos artigos.

\begin{tabular}{|c|c|}
\hline Artigo & Conceituação \\
\hline (Sartori et al.; 2008) & $\begin{array}{l}\text { "Basicamente, uma reação de oxidação-redução envolve a transferência de elétrons de uma espécie } \\
\text { para outra, ocorrendo, respectivamente, perda e ganho de elétrons, resultando em uma mudança no } \\
\text { estado de oxidação das espécies envolvidas. (...) O processo de redução ocorrerá simultaneamente } \\
\text { ao de oxidação, pois os elétrons recebidos pela espécie que se reduz serão cedidos pela espécie que } \\
\text { sofre oxidação. (...) A oxidação resulta na perda de um ou mais elétrons pela espécie (átomos, íons ou } \\
\text { moléculas). Quando ela perde elétrons, diz-se que foi oxidada e seu estado de oxidação atinge valores } \\
\text { mais positivos. O agente oxidante recebe elétrons de uma outra substância e torna-se reduzido. Por outro } \\
\text { lado, a redução é, por sua vez, o processo que resulta em ganho de um ou mais elétrons pelas espécies. } \\
\text { Quando uma espécie recebe elétrons, diz-se que ela foi reduzida e seu estado de oxidação diminui. Para } \\
\text { saber se uma dada reação de oxidação-redução vai se processar espontaneamente, é preciso consultar } \\
\text { tabelas contendo os potenciais-padrão de redução }\left(\mathrm{E}^{\circ}\right) \text { de cada uma das semireações envolvidas." }\end{array}$ \\
\hline (Carvalho et al., 2005) & $\begin{array}{l}\text { "As reações de oxi-redução envolvem perda e ganho de elétrons, onde as espécies que ganham elétrons } \\
\text { sofrem redução e as que perdem, sofrem oxidação. A Eq. (1) exemplifica um processo redox: } \\
\qquad \mathrm{Cu}+1 / 2 \mathrm{O}_{2} \rightarrow \mathrm{CuO}(1) \\
\text { onde o cobre sofre oxidação, perdendo } 2 \text { elétrons que são transferidos ao oxigênio, que é então reduzi- } \\
\text { do, formando óxido de cobre(II). O oxigênio é o agente oxidante da reação e o cobre, o agente redutor." }\end{array}$ \\
\hline
\end{tabular}

Quadro 5: Trechos de artigos que não conceituaram as reações redox.

\section{Trechos}

"A detecção da embriaguez por esse instrumento é visual, pois a reação que ocorre é a oxidação de álcool a aldeído e a redução do dicromato a cromo (III), ou mesmo a cromo (II). A coloração inicial é amarelo-alaranjada, devido ao dicromato, e a final é verde-azulada, visto ser o cromo (III) verde e o cromo (II) azul." (Braathen, 1997) (GRIFO NOSSO)

"Oxidação e esterificação: são reações de álcoois e aldeídos com oxigênio e entre álcoois e ácidos produzindo ésteres. ... Estes álcoois são oxidados produzindo aldeídos, ácidos e ésteres, que atribuirão aroma, sabor e cor à bebida." (Pinheiro et al., 2003) (GRIFO NOSSO)

"A corrosão é um processo espontâneo e passível de ocorrer quando o metal está em contato com um eletrólito, tendo início com a oxidação do metal." (Souza et al; 2007) (GRIFO NOSSO)

Quanto ao uso dos termos estado de oxidação e número de oxidação, verificamos que $71 \%$ artigos não fizeram uso dos termos em sua escrita, $17 \%$ utilizaram o termo estado de oxidação, $4 \%$ número de oxidação e ainda $8 \%$ apresentaram os dois termos (Gráfico 4).

Pelos dados obtidos observamos que os termos estado de oxidação e número de oxidação são utilizados por poucos

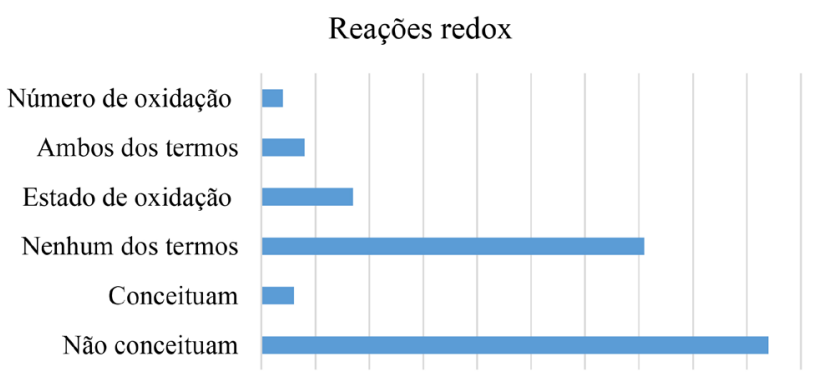

Gráfico 4: Representação percentual do critério Reações redox. artigos. No Quadro 6 destacamos alguns trechos dos artigos que utilizam os termos e verificamos que ambos são tratados como sinônimos. Este fato fica claro nos três artigos que apresentaram ambos os termos, estado de oxidação e número de oxidação (Guimarães; Nour, 2001; Martins et al., 2003; Mendonça et al., 2004). Apenas dois artigos utilizam somente o termo número de oxidação, mas nestes não houve explicação sobre a utilização do termo. Já os 9 artigos que usaram apenas o termo estado de oxidação, alguns explicavam a função do termo, como no primeiro exemplo apresentado no Quadro 6, já outros apenas citam o termo sem explicar, como no segundo exemplo do Quadro 6.

Buscamos averiguar a utilização desses termos devido ao fato de suas diferentes abordagens. Alguns autores como Atkins e Jones (2006) falam em número de oxidação, já Silverstein (2011) utiliza estado de oxidação. Nos artigos analisados há ainda os que utilizam ambos os termos em seu texto, tratando-os como sinônimos, assim como também faz o artigo de Jensen (2011). Porém, a IUPAC (p. 1049, 2014) e 
Quadro 6: Termos estado de oxidação e número de oxidação utilizados nos artigos analisados.

\begin{tabular}{|c|c|}
\hline Estado de oxidação & $\begin{array}{l}\text { "....uma reação de oxidação-redução envolve a transferência de elétrons de uma espécie para outra, ocor- } \\
\text { rendo, respectivamente, perda e ganho de elétrons, resultando em uma mudança no estado de oxidação } \\
\text { das espécies envolvidas... Quando ela perde elétrons, diz-se que foi oxidada e seu estado de oxidação } \\
\text { atinge valores mais positivos... Quando uma espécie recebe elétrons, diz-se que ela foi reduzida e seu } \\
\text { estado de oxidação diminui." (Sartori et al., 2008) (GRIFO NOSSO) } \\
\text { "No processo de oxidação, o íon ferro tem seu estado de oxidação alterado, portanto, o professor pode } \\
\text { discutir com os alunos os conceitos relativos à oxidação e redução das substâncias." (Eleotério, et al, } \\
\text { 2007) (GRIFO NOSSO) }\end{array}$ \\
\hline Número de oxidação & $\begin{array}{l}\text { "Os alunos se interessaram em compreender o fenômeno envolvido, mas pediram para revisar alguns } \\
\text { conceitos básicos como oxidação e redução; agente redutor e oxidante; e número de oxidação." (Pinheiro, } \\
\text { 2012) (GRIFO NOSSO) } \\
\text { "O tema nanotecnologia permite a discussão de vários conceitos fundamentais em química, além de Clas- } \\
\text { sificação Periódica dos Elementos, tais como funções inorgânicas, estequiometria, número de oxidação, } \\
\text { equações de oxirredução, além da preparação de soluções e transferência de líquidos..." (Rebello et al, } \\
\text { 2012) (GRIFO NOSSO) }\end{array}$ \\
\hline
\end{tabular}

Look (2011) fazem uma distinção entre os termos. Há ainda o conceito de Clayden et al (p. 35, 2001), que apresentam uma definição de nível de oxidação, sendo esta uma forma diferente de conceituação das demais. Dessa forma, esses termos ainda não são bem definidos, causam alguma confusão e isso vem sendo pouco discutido.

De acordo com a IUPAC (p. 1049, 2014), o número de oxidação de um átomo central em uma esfera de coordenação é a "carga" que deveria suportar se todos os ligantes forem removidos juntamente com os pares de elétrons que foram compartilhados com o átomo central, sendo representado por números romanos.

Já o estado de oxidação é uma medida do grau de oxidação de um átomo em uma molécula. É definido de acordo com um conjunto de regras: (1) o estado de oxidação de um elemento livre (não combinado) é zero; (2) para um íon monoatômico, o estado de oxidação é igual à carga líquida do íon; (3) hidrogênio tem um estado de oxidação de +1 e oxigênio tem um estado de oxidação de -2 na maioria dos compostos (as exceções são: o hidrogênio tem um estado de oxidação de -1 em hidretos metálicos, ex. LiH, e o oxigênio tem um estado de oxidação de -1 em peróxidos, por exemplo, $\mathrm{H}_{2} \mathrm{O}_{2}$ ); (4) a soma algébrica dos estados de oxidação de todos os átomos numa molécula neutra deve ser igual a zero, enquanto que em íons a soma algébrica dos estados de oxidação dos átomos constituintes deve ser igual à carga do íon. Quanto maior o estado de oxidação de um átomo, maior é o seu grau de oxidação; quanto menor for o estado de oxidação, maior é o seu grau de redução.
Quanto à temática ou assuntos utilizados

Finalizando nosso panorama, verificamos quais temas ou assuntos foram utilizados pelos artigos, a fim de demonstrar a variedade de assuntos e temas, reforçando, desse modo, a versatilidade das reações de oxi-redução, conforme já mencionado por Atkins e Jones (2006, p. 92). Para isso, no Quadro 2, associamos algumas das temáticas e alguns assuntos abordados nos artigos analisados com os temas que estão relacionados, destacando-se os temas: meio ambiente, tecnologia e saúde. Além disso, diversos outros conceitos químicos, envolveram também a utilização de reações redox, como a combustão, por exemplo.

Constatamos com isso que o estudo de oxi-redução pode se valer de uma grande diversidade de temas e assuntos, principalmente para contextualização do conhecimento. Além dessa característica, verificamos que o conteúdo está envolvido diretamente como o ensino de outros conceitos. Dessa forma, não há desculpa para não realizar um ensino diferenciado. Mas não basta apenas exemplificar, é preciso contextualizar, "ensinar conceitos da ciência ligados à vivência dos alunos" (Silva; Marcondes, 2014), procurando estreitar a relação entre conceitos e contextos, com vista à formação cidadã dos estudantes.

\section{Considerações Finais}

A preocupação desse trabalho foi verificar como as reações redox estão sendo exploradas pelos artigos publicados na QNEsc, devido à sua representatividade no ensino de 
Química. Com isso, encontramos uma enorme versatilidade de assuntos e diversas possibilidades para desenvolver esses conteúdos, e dessa forma fornecer uma análise dos trabalhos que vem sendo realizados, permitindo aos profissionais do ensino que irão lidar com esse conteúdo em sala de aula, novas ideias bem como, uma reflexão acerca de sua prática.

Notamos uma preocupação na realização de práticas experimentais e um ensino contextualizado, ainda com enfoque, em sua maioria, puramente científico. Porém a versatilidade e importância do conceito foram demonstradas através da análise dos diversos assuntos que podem ser utilizados para realizar seu estudo. Assim o conhecimento que estas reações proporcionam deve ser considerado muito além das questões puramente científicas.

Consideramos que os artigos analisados contribuem para um ensino mais significativo do conteúdo de reações de oxi-redução, pois este conteúdo é considerado difícil e estes artigos são resultados de intensas pesquisas na área, oferecendo uma diversidade de metodologias que podem ser exploradas. Sugerimos aos professores que utilizem estes artigos para procurar tornar sua prática mais dinâmica através das diversas atividades diferenciadas apresentadas que certamente irão auxiliar seu ensino.

\section{Referências}

ANSELME, J-P. Understanding oxidation-reduction in organic chemistry. Journal of Chemical Education, v. 74, n. 1, p. 69-72, 1997.

ARAÚJO, M. S. T. de e ABIB, M. L. V. dos S. Atividade experimentais no ensino de física: diferentes enfoques, diferentes finalidades. Revista Brasileira de Ensino de Física, v. 25, n. 2, p. 176-194, 2003.

ATKINS, P. e JONES, L. Princípios de química: questionando a vida moderna e o meio ambiente. 3 ed. Porto Alegre: Bookman, 2006.

AULER, D. Enfoque Ciência-Tecnologia-Sociedade: pressupostos para o contexto brasileiro. Ciência e Ensino, v. 1, n. especial, p. 2007.

BOCCHI, N.; FERRACIN, L. C. e BIAGGIO, S. R. Pilhas e baterias: funcionamento e impacto ambiental. Química Nova na Escola, n. 11, p. 3-9, 2000.

BRAATHEN, P. C. Hálito culpado, o princípio químico do bafômetro. Química Nova na Escola, n. 4, p. 3-5, 1997.

BRASIL. Ministério da Educação. Secretária de Ensino Básico. Parâmetros Curriculares Nacionais do Ensino Médio. Parte III, Ciências da Natureza, Matemática e suas Tecnologias, 2000.

CARVALHO, L. C. de; LUPETTI, K. O. e FILHO-FATIBELO, O. Um estudo sobre a oxidação enzimática e a prevenção do escurecimento de frutas no ensino médio. Química Nova na Escola, n. 22, p. 48-50, 2005

CLAYDEN, J.; GREEVES, N; WARREN, S. e WOTHERS, P. Organic Chemistry. 1 ed. New York: Oxford, 2001.

COSTA, T. S. et al.. A corrosão na abordagem da cinética química. Química Nova na Escola, n. 22, p.31-34, 2005.

DE JONG, O.; ACAMPO, J. e VERDONK, A. Problems in teaching the topic of redox reactions: actions and conceptions
Entretanto, devemos ter muita atenção para a significação conceitual necessária para o bom entendimento das reações de oxi-redução, pois verificamos a necessidade de aprofundar mais as discussões tanto das reações em si quanto dos usos dos termos estado de oxidação e número de oxidação. Talvez, por ser pouco explorado em termos de publicação, com poucas discussões conceituais, cause as dificuldades apresentadas no ensino e aprendizagem desse conteúdo em nível de ensino médio. Por isso, reforçamos práticas diferenciadas são muito importantes, mas devem ser acompanhadas de conceitos claramente definidos para que tanto o ensino quanto à aprendizagem possam se concretizar.

\begin{abstract}
Sabrina Gabriela Klein (sabrinaklein92@gmail.com), formada em Química Licenciatura Plena pela Universidade Federal de Santa Maria e mestranda do Programa de Pós-Graduação em Educação em Ciências: Química da Vida e Saúde, na mesma instituição. Avenida Roraima 1000, Departamento de Química, Santa Maria, RS - BR. Mara Elisa Fortes Braibante (maraefb@gmail.com), formada em Química Licenciatura pela Universidade Federal de Santa Maria (UFSM), doutora em Ciências (Química Orgânica) pela Universidade Estadual de Campinas (UNICAMP), é professora do Departamento de Química da UFSM e orientadora no Programa de Pós-graduação em Educação em Ciências: Química da Vida e Saúde na mesma instituição. Santa Maria, RS - BR.
\end{abstract}

of chemistry teachers. Journal of Research in Science Teaching, v. 33, n. 10, p. 1097-1110, 1995.

DE PAOLI, M.-A. Plásticos inteligentes. Química Nova na Escola, ed. especial, p. 9-12, 2001.

DURAND, A. M. A Química dos minerais: uma temática para investigar o papel da experimentação no ensino de ciências. Dissertação. (Mestrado em Educação em Ciência) - Universidade Federal de Santa Maria, 2015. ELEOTÉRIO, I. C. et al. Experimentos para identificação de íons ferro em medicamentos comerciais. Química Nova na Escola, n. 26, p. 37-39, 2007.

GALIAZZI, M. C. et al. Objetivos das atividades experimentais no ensino médio: a pesquisa coletiva como modo de formação de professores de ciência. Ciência \& Educação, v.7, n.2, p.249263, 2001

GIORDAN, M. O papel da experimentação no ensino de ciências. Química Nova na Escola, n.10, p. 43-49, 1999.

GUIMARÃES, J. R. e NOUR, E. A. A. Tratando nossos esgotos: processos que imitam a natureza. Química Nova na Escola, ed. especial. p. 19-30, 2001.

IUPAC - International Union of Pure and Applied Chemistry Compendium of Chemical Terminology. Gold Book. Version 2.3.3, 2014 .

JENSEN, W. B. Oxidation states versus oxidation numbers. Journal Chemical Education, v. 88, p. 1599-1600, 2011.

JOESTEN, M. D. e WOOD, J. L. Word of Chemistry. 2 ed. EUA: Sauders College Publishing, 1996.

JUNIOR, W. E. F. e DOCHI, R. S. Um experimento simples envolvendo Oxidação-redução e diferença de pressão com materiais do dia-a-dia. Química Nova na Escola, n. 23, p. 49-51, 2006

JÚNIOR, W. A. D. e WINDMOLLER, C. C. A questão do mercúrio em lâmpada fluorescente. Química Nova na Escola, n. 28, p. 15-19, 2008. 
LOOK, H. P. Expanded definition of the oxidation state. Journal Chemical Education, v. 88, n. 3, p. 282-283, 2011.

MARTINS, C. R. et al. Ciclos globais de carbono, nitrogênio e enxofre: a importância da química na atmosfera. Química Nova na Escola, n. 5, 2003.

MEDONÇA, R. J.; CAMPOS, A. F. e JÓFILI, Z. M. S. O conceito de oxidação-redução nos livros didáticos de química orgânica do ensino médio. Química Nova na Escola, n. 20, p. 45-48, 2004.

MORAIS, R. Uma tempestade de luz: a compressão possibilitada pela análise textual discursiva. Ciência \& Educação, v. 9, n.2, p. 191-211, 2003.

OLIVEIRA, J. S. Contribuições e abordagens das atividades experimentais no ensino de ciências: reunindo elementos para a prática docente. Acta Scientiae, Canoas. v. 12, n. 1, p. 139-153, 2010.

OSTERLUNND, L. L.; BERG, A. e EKBORG, M. Redox models in chemistry textbooks for the upper secondary school: friend or foe? Chemistry Education Research and Practice, 11, 182-192, 2010.

ÖSTERLUNND, L. L. e EKBORG, M. Student's understanding of redox reactions in three situation. Nordina, v. 5, n.2, 2009.

PINHEIRO, P. C. Aumentando o interesse do alunado pela química escolar e implantação da nova proposta curricular mineira: desenvolvimento e resultados de projeto seminal realizado no PIBID-UFSJ. Química Nova na Escola, v. 34, n. 4, p. 173-183, 2012.

PINHEIRO, P. C.; LEAL, M. C. e ARAÚJO, D. A. de. Origem, produção e composição química da cachaça. Química Nova na Escola, n. 18, p. 3-8, 2003.

REBELLO, G. A. F. et al. Nanotecnologia, um tema para o ensino médio utilizando a abordagem CTSA. Química Nova na Escola, v. 34, n. 1, p. 3-9, 2012.

SANTOS, W. L. P. dos. Educação CTS e cidadania: confluências e diferenças. Revista de Educação em Ciências e Matemática. v. 9 , n. 17 , p. $49-62.2012$
SARTORI, E. R. BATISTA, E. F. e FILHO-FATIBELO, O. Escurecimento e limpeza de objetos de prata - um experimento simples e de fácil execução envolvendo reações de oxidação-redução. Química Nova na Escola, n. 30, p. 61-65, 2008.

SARTORI, E. R. et al. Construção de uma célula eletrolítica para o ensino de eletrólise a partir de materiais de baixo custo. Química Nova na Escola, v. 35, n. 2, p. 107-111, 2013.

SILVA, E. L. da e MARCONDES, M. E. R. Contextualização no ensino de ciências: significados e epistemologia. In: Tópicos em ensino de química. Org: Santana, E. M de; SILVA, E. L. da. São Carlos: Pedro \& João Editores, 2014.

SILVERSTEIN, T. Oxidation and reduction: too many definitions? Journal of Chemical Education, v. 88, n. 3, p. 279-281, 2011.

SOUZA, E. T. de et al. Corrosão de metais por produtos de limpeza. Química Nova na Escola, n. 26, p. 44-46, 2007.

SUART, R. de C. Habilidade cognitivas manifestadas por alunos do ensino médio de química em atividades experimentais investigativas. Dissertação de mestrado. Universidade de São Paulo. São Paulo, 2008.

VAZ, E. L. da S.; ASSIS, A. e CODARO, E. N. Análise experimental da resistência à corrosão e da velocidade de corrosão: uma proposta pedagógica. Química Nova na Escola, v. 33, n. 1, p. 61-64, 2011.

\section{Para Saber Mais}

MENZEK, A. A new approach to understanding oxidation-reduction of compounds in organic chemistry. Journal of Chemical Education. v. 79, n. 6, p. 700-702, 2002.

OSTERLUNND, L. L.; BERG, A.; EKBORG, M. Redox models in chemistry textbooks for the upper secondary school: friend or foe? Chemistry Education Research and Practice, 11, 182-192, 2010. Disponível em: <http://pubs.rsc.org/en/content/ articlepdf/2010/rp/c005467b > . Acesso em: 06/08/2015.

\footnotetext{
Abstract: Oxidation-reduction reactions and their different approaches. This paper aims to present an overview of how the content of oxidation-reduction reactions considered difficult to teaching and learning has been developed in the classroom, in order to demonstrate its several educational possibilities as well as to discuss its implications. To accomplish this overview, we conducted a search for published articles in QNEsc journal that addressed the content of oxidation-reduction reactions, in which were found 52 articles. To do this, we chose some criteria for the verification of approaches and each criterion was classified in categories that allowed a discussion about the way the teaching of redox content has been developing. Thus, we observed the diversity of subjects that can be used as a manner of contextualization for addressing the redox reactions and also the variety of experimental activities. However, we found some conceptual discussions about this subject in the literature.

Keywords: Oxidation-reduction education; QNESC research article survey; oxidation-reduction reactions.
} 